All course materials, includ-

ing the original lecture, are

available as webcasts/pod-

casts at www.ers-education.

org/sdb2009.htm

\title{
Morbidity and mortality of sleep-disordered breathing: obstructive sleep apnoea and car crash
}

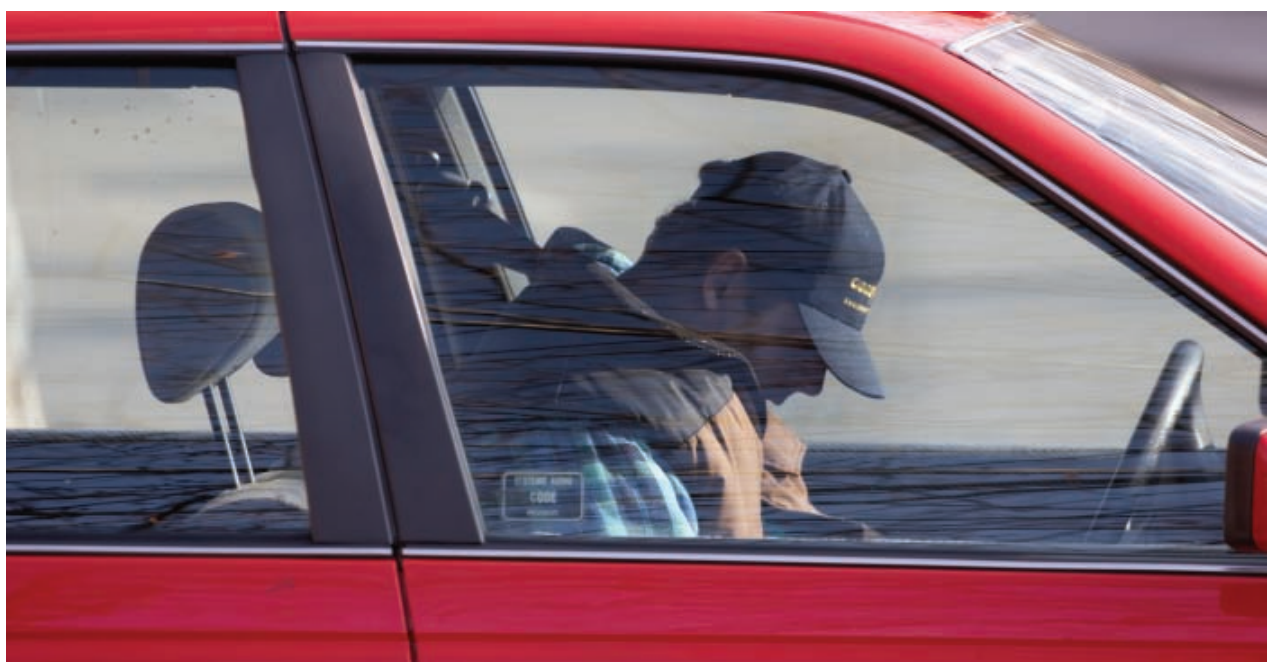

\section{Provenance}

Adapted from an ERS School Course.

\section{Competing interests}

B. Phillips is a consultant for the Federal Motor Carrier Safety Administration (Washington $D C$, USA), Ventus and Cephalon (Frazor, PA, USA). B. Phillips has received speaking honorarium from ResMed (Abingdon, UK) and Respironics (Murrysville, $P A, U S A)$.

\section{Educational aims}

1 To review the results of USA Department of Transportation meta-analysis regarding obstructive sleep apnoea (OSA) and car crash risk.

I To discuss factors beyond OSA that increase the risk of crash.

\section{Summary}

Untreated OSA increases the risk of having a car crash two-fold. In addition, the severity of sleep-disordered breathing, degree of oxygen desaturation, self-reported sleepiness and body mass index (BMI) increase the risk of crash in OSA patients. Continuous positive airway pressure (CPAP) reduces the risk of car crash. The data are insufficient for other forms of treatment to date. Sleep loss, medications and driving conditions have also been found to be factors affecting the risk of crash.

Approximately 5,000 people are killed each year from commercial motor vehicle crashes in the USA [1]. At least 1,120 of these accidents have been associated with sleep-related disorders [2]. In the UK, fatal road traffic accidents cost over $£ 1$ million annually, resulting in a huge burden on society [3]. This article summarises the currently available literature on the association between car crash and OSA and other factors related to crash.
HERMES syllabus link: module B.19 


\section{Does OSA increase the risk of car crash?}

OSA causes fragmented sleep patterns, leading to impaired vigilance, delayed reaction times and daytime sleepiness, which are likely to play a role in traffic accidents. The evidence so far suggests that drivers with OSA are at an increased risk of motor vehicle crash when compared with comparable drivers who do not have the disorder. In1999, GEORGE and SMILEY [4] reported results of the first study to include $>1,000$ subjects using controls and data from an accident record system. They found that the accident rate in patients with OSA with an apnoea/hypopnoea index (AHI) $>40$ events per $h$ was double that of controls. A study from Japan including 448 subjects found that the accident rate was almost three times higher in those with an $\mathrm{AHI}>30$ compared with those with an $\mathrm{AHI}<5$ [5]. In addition, a Spanish study discovered a two-fold higher accident rate in 60 patients with OSA compared with 60 controls [6]. A meta-analysis that included 40 studies on OSA and the risk of crash confirms the earlier reports stating that noncommerical drivers with OSA are at a statistically significant increased risk of involvement in motor vehicle crash [7].

Currently the majority of the literature is

Figure 1

Completed ESS where the patient thought there was a much greater chance than a high chance of dozing and decided to add another category and to use 4, rather than 3, to indicate a high likelihood of dozing. based on noncommercial drivers with very few studies focusing on commercial drivers. However, it has been found that $20-30 \%$ of accidents involving commercial drivers are sleep related [2]. Some studies have also suggested that there may be a higher level of sleep-disordered breathing among drivers of heavy vehicles $[8,9]$.

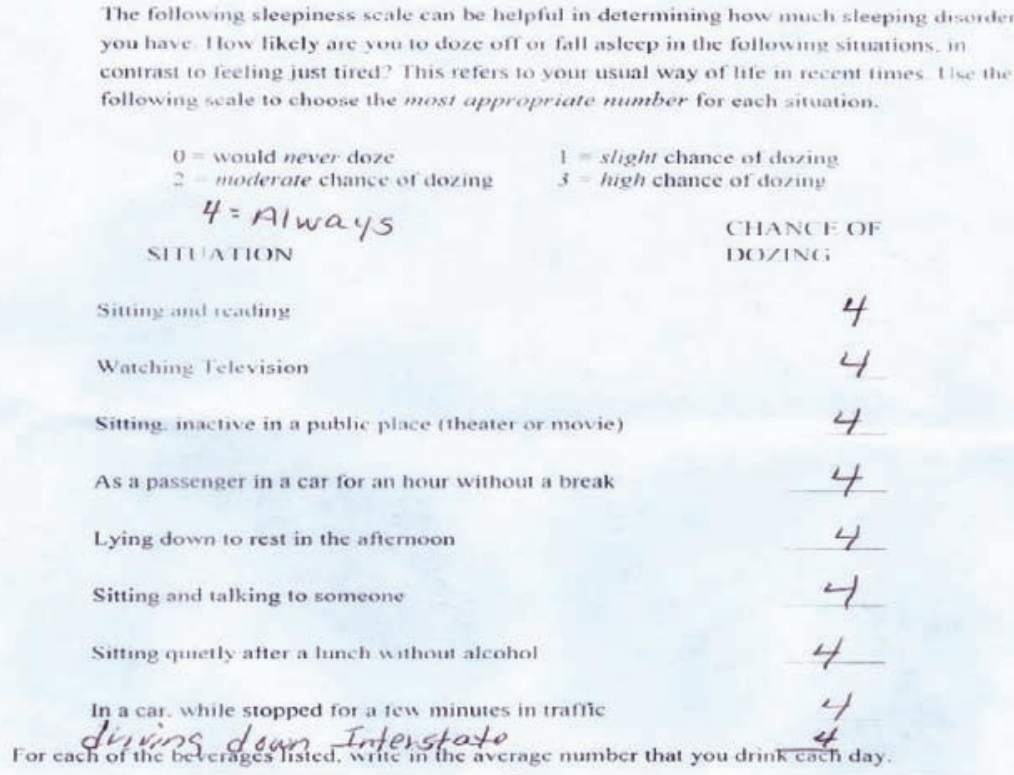


not have OSA; however, it is obvious that not everyone who has OSA will crash. Thus, while higher $\mathrm{BMI}, \mathrm{AHI}$ and ESS suggest an increased likelihood of crash (along with lower oxygen saturation), there are no tests that can precisely predict which subset of OSA patients are at an increased risk.

A number of portable sleep monitoring systems, though unmonitored and therefore not as accurate as the current reference standard (a sleep study in a specialised sleep laboratory), offer an alternative method by which severity of OSA may be assessed in a large number of individuals at a low cost. This is a useful tool because OSA patients with severe disease are involved in a higher number of crashes than mild OSA patients.

\section{Are any treatments available to reduce the risk of crash in OSA patients?}

Continuous positive airway pressure (CPAP) is the treatment of choice for patients with OSA and is effective in improving daytime sleepiness [13-15]. Several studies have investigated the possibility that CPAP reduces the risk of traffic collisions in patients with OSA and all noted a reduction in the risk of a car accident after treatment with CPAP [16-19].

A Japanese study examined the rate of traffic accidents before and after treatment with nasal CPAP using the ESS in 75 male patients with OSA [16]. Patients were evaluated after 2 yrs of treatment with a questionnaire enquiring about their use of CPAP, ESS, self-related depression scale and driving history. In total, 46 responders had continued CPAP treatment for 2 yrs and reported no traffic accidents in this period in comparison with 33\% of patients having accidents prior to treatment. This study shows a reduced risk after treatment with CPAP, but relies on selfreported accidents and does not have a control group.

A study by GEORGE [17] included 210 patients with OSA who were being treated with CPAP and 210 randomly selected age and sex-matched controls. Motor vehicle crash data were obtained from the Ontario Ministry of Transportation and compared for the 3 yrs before and after treatment with CPAP for the patients and for the corresponding time frame for controls. It was found that prior to CPAP treatment OSA patients had a higher rate of crash than the control subjects; however, following CPAP treatment the crash rate of the OSA group fell to a normal level. Therefore, CPAP removed the increased risk of crash caused by OSA.

A more recent study had similar results when comparing the number of motor vehicle accidents in 80 healthy subjects with 80 patients with OSA during the 2 yrs before and after CPAP treatment was initiated [19]. The results of the study showed that the risk of a car accident was significantly reduced when OSA patients commenced CPAP treatment. However, the results of the study did not support a direct role of CPAP because a similar rate of reduction was seen in control subjects. This could be due to the diagnosis of OSA itself reducing risk as it alerts the driver to be more vigilant and responsible at the wheel when feeling sleepy.

To date, no other treatments used in general practice for OSA (for example medication, dental appliances and upper airway surgery) have been shown to reduce the rate of car crash [11]. Although other technologies may reduce crash risk among individuals with moderate-to-severe OSA, the available evidence to support this is not convincing. Therefore, no conclusions can be made at present regarding other available technologies for the treatment of OSA. Currently, it is also not clear what length of time is required following initiation of an effective treatment to reach a degree of improvement that would permit safe driving.

\section{Are there any crash- related factors beyond OSA? \\ Sleep duration}

The most common cause of sleepiness is not sleep apnoea it is actually a lack of sleep; therefore, this may be an important factor for the risk of crash. A study by PACK et al. [20] used the ESS to measure subjective sleepiness and the MSLT to measure objective sleepiness in 247 and 159 commercial drivers with high and low risk of apnoea, respectively. The study showed that both subjective and objective sleepiness were common in commercial drivers and demonstrated that sleep duration is a risk factor for subjective sleepiness, objectively measured sleepiness and performance impairments (figure 2). Performance impairments were similar in drivers who slept an average of $<5 \mathrm{~h}$ per night and drivers with severe sleep apnoea. However, severe sleep apnoea was only present in $4.7 \%$ of the study sample compared with $13.5 \%$ of the population having $<5 \mathrm{~h}$ sleep per night. 

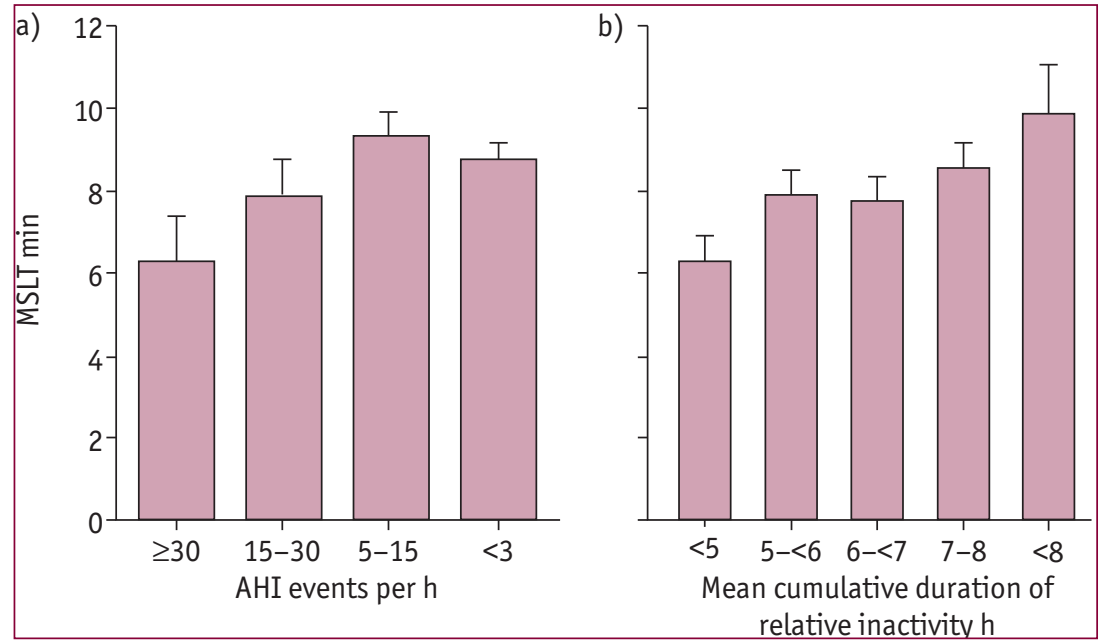

Figure 2

Least-squares estimates of mean MSLT with standard errors controlling for apnoea severity category, sleep duration category, age, sex and BMI. a) AHI category. b) Mean length of cumulative duration of relative inactivity. Reproduced from [19] with permission from the publisher.
Thus, sleep deprivation is likely to be a more common cause of driving impairment than OSA.

\section{Hypnotics}

All Norwegians (3.1 million) aged 18-69 yrs were followed-up over a 19-month period in order to examine the rate of traffic accidents associated with benzodiazepinelike hypnotics [21]. Data on prescriptions, road traffic accidents and emigration/death was obtained from three Norwegian population-based registries. Standardised incidence rates (SIRs) showed that flunitrazepam use was associated with a fourfold increase in crash rate, zopiclone and zolpidem doubled the crash rate and nitrazepan use was associated with roughly triple the rate of accidents. The highest SIR for crash was found among the youngest users for all hypnotics. Therefore, this study strongly suggests that the use of hypnotics increases the rate of car crash.

\section{Other factors}

A study carried out on 2,342 commercial drivers in Australia measured the prevalence of excessive sleepiness and sleep-disordered breathing and assessed other accidental risk factors [22]. It found that almost $60 \%$ of drivers had sleep-disordered breathing, 16\% had OSA and $24 \%$ had excessive sleepiness. The sleepiest $5 \%$ of drivers identified by the ESS and Functional Outcomes of Sleep Questionnaire had both an increased risk of accidents and multiple accidents. Interestingly, the study also demonstrated an increased risk of crash for the use of narcotics analgesics, antihistamine use, more time spent driving per week, interstate and country driving and younger age.

\section{Conclusions}

Untreated OSA increases the risk of crash by approximately twice. The severity of OSA, degree of oxygen desaturation, self-reported sleepiness (ESS) and BMI (as an independent factor) all affect the risk of car crash. CPAP has been shown to reduce the rate of accidents, but to date no other treatments can be recommended. Importantly, sleep apnoea is not the only risk factor for car crash; insufficient sleep, narcotics, antihistamines and driving conditions have been shown to play a role in the rate of car accidents.

\section{References}

1. Federal Motor Carrier Safety Administration. Large truck crash overview._www.fmcsa.dot.gov/facts-research/researchtechnology/report/2007LargeTruckCrashOverview.pdf Date created: December 2008.

2. Akerstedt T. Consensus statement: fatigue and accidents in transport operations. J Sleep Res 2009; 9: 395

3. Douglas NJ, George CF. Treating sleep apnoea is cost effective. Thorax 2002; 57: 93.

4. George CF, Smiley A. Sleep apnea and automobile crashes. Sleep 1999; 22: 790-795.

5. Shiomi T, Arita AT, Sasanabe R, et al. Falling asleep while driving and automobile accidents among patients with obstructive sleep apnea-hypopnea syndrome. Psychiatry Clin Neurosci 2002; 56: 333-334.

6. Barbe F, Pericas J, Munoz A, et al. Automobile accidents in patients with sleep apnea syndrome. An epidemiological and mechanistic study. Am J Respir Crit Care Med 1998; 158: 18-22.

7. Ellen RLB, Marshall SC, Palayew M, et al. Systemic review of motor vehicle crash risk in persons with sleep apnea. J Clin Sleep Med 2006; 2: 193-200.

8. Hui D, Chan J, Ko F, et al. Prevalence of snoring and sleep-disordered breathing in a group of commercial bus drivers in Hong Kong. Intern Med J 2002; 32: 149-157.

9. Stoohs RA, Bingham LA, Itoi A, Guilleminault C, Dement WC. Sleep and sleep-disordered breathing in commercial longhaul truck drivers. Chest 1995; 107: 1275-1282.

10. Johns MV. A new method for measuring tdaytime sleepiness: the Epworth sleepiness scale. Sleep 1991; 14: 540-545.

11. Ancoli-lsrael S, Czeisler CA, George CFP, Guilleminault C, Pack Al. Obstructive sleep apnea and commercial motor vehicle driver safety. www.fmcsa.dot.gov/rules-regulations/TOPICS/mep/report/Sleep-MEP-Panel-Recommendations-508. pdf Date created: January 14, 2008.

12. Mulgrew AT, Nasvadi G, Butt A, et al. Risk and severity of motor vehicle crashes in patients with obstructive sleep apnoea/hypopnoea. Thorax 2008; 63: 536-541.

13. Smith PL, Hudgel DW, Olson LG, et al. Indications and standards for use of nasal continuous positive airway pressure (CPAP) in sleep apnea syndromes. Am J Respir Crit Care Med 1994; 150: 1738-1745. 
14. Montserrat JM, Ferrer M, Hernandez $L$, et al. Effectiveness of CPAP treatment in daytime function in sleep apnea syndrome - a randomized controlled study with an optimized placebo. Am J Respir Crit Care Med 2001; 164: 608-613.

15. Davies RJO, Stradling JR. The efficacy of nasal continuous positive airway pressure in the treatment of obstructive sleep apnea syndrome is proven. Am J Respir Crit Care Med 2000; 161: 1775-1776.

16. Yamamoto H, Akashiba T, Kosaka N, Ito D, Horie T. Long-term effects nasal continuous positive airway pressure on daytime sleepiness, mood and traffic accidents in patients with obstructive sleep apnoea. Respir Med 2000; 94: 87-90.

17. George CF. Reduction in motor vehicle collisions following treatment of sleep apnoea with nasal CPAP. Thorax 2001; 56: 508-512.

18. Findley L, Smith C, Hooper J, Dineen M, Suratt PM. Treatment with nasal CPAP decreases automobile accidents in patients with sleep apnea. Am J Respir Crit Care Med 2000; 161: 857-859.

19. Barbe F, Sunyer J, de la Pena A, et al. Effect of continuous positive airway pressure on the risk of road accidents in sleep apnea patients. Respiration 2007; 74: 44-49.

20. Pack Al, Maislin G, Staley B, et al. Impaired perfomance in commercial drivers. Role of sleep apnea and short sleep duration. Am J Respir Crit Care Med 2006; 174: 446-454.

21. Gustavsen I, Bramness JG, Skurtveit S, Engeland A, Neutel I, Mørland J. Road traffic accident risk related to prescription of the hypnotics zopiclone, zolpidem, flunitrazepam and nitrazepam. Sleep Med 2008; 9: 818-822.

22. Howard ME, Desai AV, Grunstein RR, et al. Sleepiness, sleep-disordered breathing, and accident risk factors in commercial vehicle drivers. Am J Respir Crit Care Med 2004; 170: 1014-1021. 